\title{
Comunicación para la ciencia, una ruta hacia la visibilidad en la Universidad Autónoma de Bucaramanga (UNAB)
}

\author{
Communication for Science, a Route to Visibility at the Autonomous \\ University of Bucaramanga (UNAB)
}

\section{Comunicação para a ciência, uma via de visibilidade na Universidade Autônoma de Bucaramanga (UNAB)}

Saber cómo llegar y para quién se escribe sin perder el nivel de complejidad, sacándolo del metalenguaje científico y haciéndolo comprensible, es una ardua tarea que aprovecha las plataformas tecnológicas y diferentes estrategias de comunicación para lograr el acceso al conocimiento, de esta forma y siendo coherentes con la responsabilidad social que tienen las Instituciones de Educación Superior de llevar la educación a todas partes, y en congruencia con su función sustantiva y sus ejes misionales: docencia, investigación y extensión; con miras a cumplir el objetivo, las instituciones gestionan procesos editoriales con el fin de consolidar y potenciar una propuesta de visibilidad Institucional, más que de rentabilidad.

Una radiografía generalizada para la mayoría de las editoriales universitarias que han centrado sus esfuerzos en apoyar la producción intelectual han desembocado lamentablemente en "bodegas repletas de libros que se acumulan, ...que fueron utilizados en pequeñas cantidades para alguna actividad de prensa y como exigua retribución al autor o los autores" (1) situación que pone de manifiesto la necesidad de tomar la ruta de la comunicación para la ciencia, en donde el proceso editorial sirve de mediador entre la universidad y la sociedad, el ideal, para que realmente sea útil y cumpla una función social, en la vía de lograr la democratización del conocimiento y por ende la apropiación social del mismo.

De la premisa de que la comunicación es transversal a la gestión Institucional, es un ejercicio dialógico constante entre quienes participan y dinamizan los diferentes procesos y actividades cotidianas de una Universidad. Es por ello que la apuesta de la Universidad Autónoma de Bucaramanga (UNAB) desde este año, va encaminada a fortalecer la visibilidad Institucional mediante el proyecto estratégico "Comunicación para la Ciencia", el cual se integra y alinea con otros proyectos y lineamientos universitarios. El eje central de esta propuesta se basa en el aumento del factor de visibilidad de la UNAB en diversas instancias de orden Nacional e Internacional, a partir de un portafolio de publicaciones que incluye revistas seriadas, libros de investigación, libros de difusión, cartillas, boletines informativos y trabajos de grado, entre otros, en congruencia con lineamientos de calidad, pertinencia, valor agregado y transferencia del conocimiento, basados en los 4 pilares de la comunicación para la ciencia: la difusión, la divulgación, la legalización y la distribución.

Ahora bien, desde la complejidad inmersa tanto en la gestión del conocimiento, insumo fundamental de la propuesta de comunicación para la ciencia, como en la gestión editorial basada en los 4 pilares, la Universidad reconoce las ventajas que representan servicios tercerizados de tecnología y gestión digital del conocimiento, infraestructura tecnológica de punta requerida y canales de acceso adecuados para el público objetivo de la propuesta de comunicación. Es por ello que desde cada uno de los pilares se establecieron directrices y operadores internos y externos para el proceso.

En el caso del pilar de difusión: este se enfoca en la gestión de un entorno de I+D (investigación y desarrollo), generando métricas desde la información y comunicación 
para la ciencia, traducidas en cienciometría, infometría o bibliometría, en donde se ponen en juego las exigencias, en términos de calidad, que la comunidad científica establece por campos de formación, excelencia en el proceso de edición, comités editoriales y científicos conformados por reconocidos científicos nacionales e internacionales, evaluación por pares, seguimiento a normas y marcación de artículos, así como trabajos de investigación innovadores. El segundo pilar de este proyecto estratégico es la divulgación, la apropiación social del conocimiento, cuya base es traducir el conocimiento, el metalenguaje científico a un lenguaje accesible a la sociedad en general, mediante diferentes acciones y estrategias como el establecimiento del repositorio Institucional, un acucioso trabajo de periodismo científico, redes sociales y el apoyo de otros medios y proyectos estratégicos de la Universidad.

El tercer pilar de la comunicación y de la calidad, está dado a partir de los procesos de legalización y de propiedad intelectual de cada uno de los tipos de publicaciones a desarrollarse, tal es el caso de: registro de los números internacionales de normalización para publicaciones International Standard Serial Number (ISSN), International Standard Book Number (ISBN), International Standard Music Number (ISMN), como un compromiso legal nacional e internacional; así mismo el depósito legal para la preservación de la memoria y el patrimonio cultural, todo ello respaldado por el comité editorial UNAB quien definirá las políticas y asuntos administrativos propios de un fondo comunicación para la ciencia universitario, siendo la brújula que orienta las decisiones académicas y asume una posición crítica ante las diversas publicaciones editables en potencia y todo lo relacionado con sus asuntos legales, de la gestión de edición.

Finalmente, el pilar de distribución es el encargado de hacer posible que las diversas publicaciones editadas por la Universidad lleguen al público objetivo de manera efectiva y por los canales adecuados. Para ello, la disponibilidad del conocimiento en plataformas internas y externas de distribución en formatos impresos o digitales, de acceso abierto o restringido, en diversos formatos para los diferentes dispositivos tecnológicos existentes, en superficies virtuales de compra de conocimiento con diversidad de formas de pago, son unas de las condiciones iniciales para el trabajo de distribución acorde a las necesidades de la comunicación para la ciencia en el entorno UNAB, generando las mezclas adecuadas entre las publicaciones para un mercado en constante cambio, acercando el conocimiento de primera mano al público cambiante demandando permanente innovación en la forma de trasmitir la cultura, la ciencia y el conocimiento.

Es así, que la estrategia de comunicación para la ciencia UNAB permeará al portafolio de comunicaciones en donde se encuentran publicaciones seriadas como es el caso de la Revista MedUNAB, desde el área de Salud y Psicosociales, convirtiéndose cada una de nuestras publicaciones en la herramienta para que el conocimiento, como bien intangible en instituciones de carácter educativo, potencie su valor tanto al interior de la organización como para la sociedad, transformándose en el motor para el desarrollo y la visibilidad institucional en correspondencia con los preceptos Nacionales e Internacionales de calidad en torno a la divulgación y democratización del conocimiento.

Gerly Carolina Ariza Zabala, Ing. Msc. Ing. Área Informática y Ciencias de la Computación Coordinador de Gestión del Conocimiento Dirección de Investigaciones Universidad Autónoma de Bucaramanga

Lucía Ramírez Carrero. Cs. Msc. Ciencia Política Directora de Publicaciones Comunicación Organizacional Universidad Autónoma de Bucaramanga

\section{Referencias}

1. Sablich L, Basso S. La producción de textos universitarios y su visibilidad. Colombia: Unilibros de Colombia; 2016: 19-23. 